\title{
ANÁLISE QUALIQUANTITATIVA DE INDIVÍDUOS ARBÓREOS DAS PRAÇAS CENTRAIS DO MUNICÍPIO DE LEME, SP
}

\author{
Juliana Carange Tischer ${ }^{1}$, Alexandre Ramos Forte ${ }^{2}$, Cristiano Pedroso-de-Moraes ${ }^{3}$
}

\section{RESUMO}

Planejar a arborização é indispensável para o desenvolvimento urbano e fundamental na salubridade ambiental, por ter influência direta sobre o bem-estar do homem em razão dos múltiplos benefícios proporcionados. O presente trabalho teve por objetivo identificar as espécies arbóreas de três praças da região central do município de Leme, SP. O método de inventário utilizado foi o Censo. A avaliação dos indivíduos arbóreos constou da determinação da espécie com suas variáveis dendrométricas, tais como: classe de altura $(\mathrm{m})$, diâmetro a altura do peito - DAP $(\mathrm{cm})$ e estado fitossanitário. Também foi calculada a frequência de cada espécie e o índice de diversidade de espécies. Os resultados demonstraram, segundo índice proposto por Margalef, alta diversidade de espécies, sendo que as famílias botânicas representadas em maior número foram: Fabaceae (11 espécies), Bignoniaceae (sete) e Arecaceae (cinco). Aproximadamente 64\% dos indivíduos são nativos; $30 \%$ das árvores apresentaram DAP superior a $46 \mathrm{~cm}$ e estado fitossanitário satisfatório; a maioria dos indivíduos amostrados apresentou altura superior a nove metros. Conclui-se que a arborização nas praças centrais deste município é composta por indivíduos em idade avançada e embora apresentem grande porte e bom estado fitossanitário, o município ainda não conta com a cobertura arbórea adequada, sendo necessário, portanto, elaborar um plano diretor municipal para a arborização urbana.

Palavra-chave: Arborização; Planejamento urbano; Fitossanidade.

Recebido em 11.04.2013 e aceito em 08.05.2015

1 Bióloga, Mestranda em Química na Agricultura e Ambiente CENA/USP, Piracicaba, SP. jtischer@usp.br

2 Engenheiro Florestal (UNESP), Chefe do Núcleo de Arborização Urbana - Secretaria Municipal do Meio Ambiente. Leme, SP. alexandreramosforte@gmail.com

3 Dr. em Biologia Vegetal (UNESP), Professor Assistente de Botânica do Centro Universitário Hermínio Ometto - Uniararas. Araras, SP.cpmoraes@gmail.com 


\section{QUALITATIVE AND QUANTITATIVE ANALYSIS OF ARBOREOUS INDIVIDUALS OF THE CENTRAL SQUARES OF THE MUNICIPALITY OF LEME, SP}

\section{ABSTRACT}

Plan the arborization is essential for urban development and fundamental for environmental salubrity because the direct influence on the welfare of man due the multiple benefits provided. The present work aimed to raise the number of arboreous species existing in three central prams in Leme city, SP. The inventory method used, was the Census. The evaluation of individual trees was determined by dendrometric variables; class height $(\mathrm{m})$, diameter at breast height - DBH $(\mathrm{cm})$ and plant health. It was also calculated the frequency of each species and the species diversity index. The results showed, according to the indication proposed by Margalef, higher species diversity and the botanical families more presents were: Fabaceae (11 species), Bignoniaceae (seven) and Arecaceae (five). About $64 \%$ are native individuals; $30 \%$ of trees had DBH exceeding $46 \mathrm{~cm}$ and plant health satisfactory, most of the individuals had exceeding nine meters height. It was concluded that the arborization in the central prams of this town is comprised of individuals in old age stage, higher and in good phytossanitary state, the city do not present an adequate arboreal cover, being necessary therefore, to establish a municipal master plan for urban forestry.

Keywords: Arborization; Urban planning; Plant health.

\section{INTRODUÇÃO}

O Município de Leme tem sua população estimada em 91 mil habitantes (IBGE, 2013), privilegiados com inúmeras praças, tanto nos bairros periféricos como na região central, oferecendo um ambiente propício para o laser e descanso.

Praças, prédios públicos e privados, são elementos vivos da história das cidades. É nesse sentido que todo o patrimônio cultural e histórico pode retratar os fatos da história 
local. Com as praças em ambientes urbanos, o cidadão passou a conviver entre árvores, cimento e concreto (SOUZA; POLETTO, 2007).

As praças e jardins públicos caracterizam-se por apresentar espaços e áreas verdes que ajudam a manter o clima ameno nas áreas urbanas, retenção e ciclagem da água, contenção do vento, e ainda dão condições de sobrevivência para algumas espécies da fauna local. Assim, antes de serem "públicas", as praças são componentes importantes no ecossistema urbano, uma vez que dispõe de um espaço natural dentro de ambientes artificiais. Também se estima o valor paisagístico e cultural do local, onde fatos históricos e sociais permearam sua existência (ALMEIDA et al., 2004).

A arborização urbana também é positiva no fomento ao turismo, incentivando atividades lúdicas e físicas, associadas à diminuição do sedentarismo e desenvolvimento da educação ambiental; agregando valores políticos, sociais e econômicos (BIONDI; ALTHAUS, 2005).

Desse modo, tal prática tem o propósito de afirmar a qualidade de vida nos centros urbanos (MALAVESI; MALAVESI, 1994) atuando diretamente na qualidade do clima, paisagem e até mesmo sobre o nível de ruído disposto pelo aglomerado de pessoas nas cidades, melhoria do microclima; pela retenção de umidade do solo e do ar, redução da velocidade do vento e abrigo de fauna, sendo este último quesito capaz de propiciar uma variedade maior de espécies que influenciarão positivamente no ambiente ao equilibrar as cadeias alimentares bem como pragas e agentes vetores de doenças (MONTOYA VILCAHUAMAN, 2000; SANTOS; TEIXEIRA, 2001; GONÇALVES et al., 2004).

Além disso, vale salientar o sequestro de $\mathrm{CO}_{2}$ pela vegetação, pois, a arborização representa um papel importante na captura do carbono atmosférico no ambiente urbano, uma vez que a vegetação absorve esse gás por meio da fotossíntese (MUNEROLI; MASCARÓ, 2010). Segundo dados da Prefeitura Municipal de Manaus (2008), estima-se que cada árvore em crescimento pode absorver até 180 quilos de gás carbônico da atmosfera por ano, principalmente, as que têm o crescimento mais lento, pois a partir do plantio, a árvore já começa a realizar o sequestro do $\mathrm{CO}_{2}$ atmosférico, só diminuindo esta atividade na fase adulta.

Em Leme, as praças são utilizadas diariamente pela população para passeios, caminhadas e lazer. Neste período em que visitam as praças, a população interage com o meio, exercendo grande influência sobre o mesmo, pois além das atividades recreativas, os frequentadores estão em um íntimo contato com a natureza.

Nesse sentido, destaca-se a importância do planejamento urbano em relação às áreas verdes. Planejar a arborização é indispensável para o desenvolvimento urbano, para 
não acarretar prejuízos ao meio ambiente, considerando que a arborização é um fator fundamental na salubridade ambiental, por ter influência direta sobre o bem-estar do homem em razão dos múltiplos benefícios que proporciona ao meio (DANTAS; SOUZA, 2004).

Para tanto, os requisitos básicos são planejar harmoniosamente $\mathrm{e}$ concomitantemente a arborização e as intervenções urbanas, programar o atendimento permanente das necessidades da arborização e assegurar condições essenciais à concretização dos programas de arborização (MESQUITA, 1996; GONÇALVES et al., 2004).

Com o recente crescimento da arboricultura no Brasil, gestores municipais têm voltado atenção quanto à qualidade das árvores que ocupam os espaços urbanos na busca da otimização de suas diversas funções. Desta maneira, algumas pesquisas demonstram um forte interesse no estudo de metodologias que permitem avaliar em que condições se encontram as florestas urbanas, buscando a elaboração de projetos administrativos mais eficientes (SCHALLENBERGER et al., 2010).

Para implantar a arborização é fundamental escolher as espécies e avaliar alguns critérios, como o ritmo e as exigências para o crescimento, o tipo de copa, o porte, a folhagem, as flores, os frutos, os troncos, as raízes, os problemas de toxidez, a rusticidade, a resistência, a desrama natural e a origem das espécies (PAIVA, 2000).

O processo de avaliação da arborização, tanto qualitativo como quantitativo depende, assim, da realização de inventários que em função de objetivos especialmente definidos serão fundamentados em diferentes metodologias e poderão apresentar diferentes graus de precisão (REDING et al., 2010).

Nesse sentido, o presente trabalho teve como objetivo levantar o número de árvores existentes em três praças distribuídas na região central do município de Leme, SP, avaliando fatores como número, diversidade e frequência de espécies, porte dos indivíduos e estado fitossanitário, além de procurar diagnosticar a sua composição florística, fornecendo subsídios para um melhor entendimento sobre esse aspecto tão importante na busca de uma melhor qualidade de vida para todos. Pretende-se ainda, colaborar para um trabalho futuro de reorganização paisagística da cidade, servindo de suporte para um maior embasamento técnico sobre a arborização urbana municipal. 


\section{MATERIAIS E MÉTODOS}

A pesquisa foi realizada na cidade de Leme/SP, situada na Bacia do Rio Mogi Guaçu, que atravessa o município no sentido norte-sul, a cerca de $15 \mathrm{~km}$ da zona urbana (PREFEITURA DO MUNICÍPIO DE LEME, 2015).

De acordo com o Instituto Brasileiro de Geografia e Estatística IBGE (2013), o município estima aproximadamente 91 mil habitantes. Segundo a classificação de Köppen, o clima da região é do tipo "Cwa", com verão chuvoso entre os meses de outubro a março, e inverno seco entre os meses de maio a setembro. A precipitação pluviométrica média anual é de $1.388,5 \mathrm{~mm}$ e a média anual de temperatura é de $22^{\circ} \mathrm{C}$ (PREFEITURA DO MUNICÍPIO DE LEME, 2015).

Os solos predominantes na região são os latossolos roxos, vermelho escuro, vermelho amarelo e podzólico vermelho amarelo, indicando aptidão agrícola. A vegetação predominante pertence à Floresta Estacional Semidecidual (PREFEITURA DO MUNICÍPIO DE LEME, 2015).

Todos os indivíduos arbóreos, com DAP (diâmetro a altura do peito) superior a cinco centímetros, foram contabilizados nas três principais praças centrais de Leme: Praça da Bíblia (Área 1); Praça Rui Barbosa (Área 2); Praça Igreja Imaculada Conceição e EE "Profa. Maria Joaquina de Arruda" (Área 3), no mês de julho de 2012 (FIGURA 1).

Figura 1. Município de Leme: áreas amostrais

Figure 1. City of Leme: sample areas

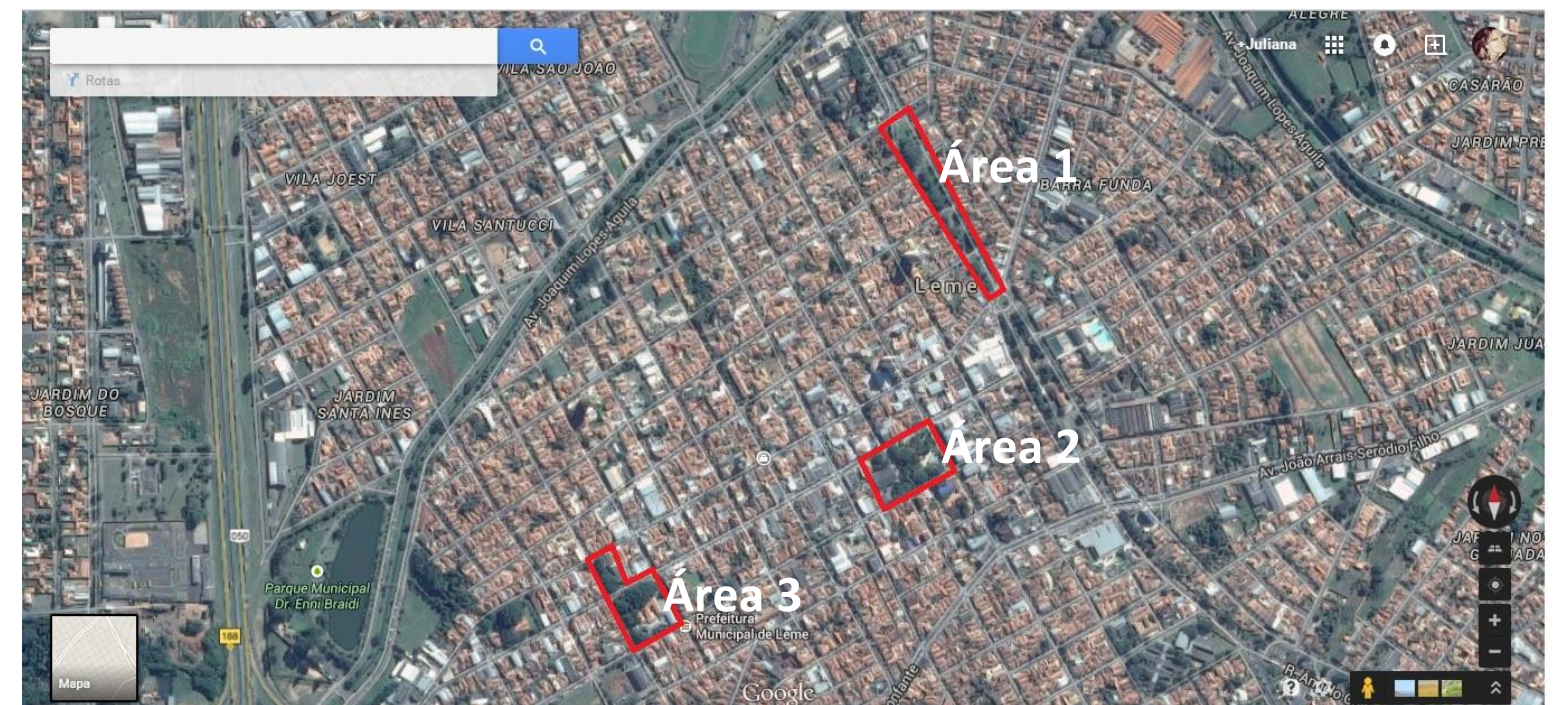

Área 1: Praça da Bíblia. Área 2: Praça Rui Barbosa. Área 3: Praça Igreja Imaculada Conceição. Area 1: Bible's Plaza Area 2: Rui Barbosa Plaza. Area 3: Imaculada Conceição's Church Plaza

Fonte: Google Imagens, 2014. 
O método de inventário utilizado foi o Censo (100\%), no qual a literatura descreve como sendo apropriado para pequenas áreas florestadas ou áreas com pequeno número de indivíduos, uma vez que a medição de muitos indivíduos constitui atividade com grande dispêndio de tempo e com custo muito elevado (SOARES et al., 2007).

A avaliação dos indivíduos arbóreos constou da determinação da espécie com suas variáveis dendrométricas; como classe de altura $(\mathrm{m})$, diâmetro a altura do peito - DAP $(\mathrm{cm})$ e estado fitossanitário.

Para altura os indivíduos foram classificados em: classe I $(<3 \mathrm{~m})$, classe II $(3,1-9$ m) e classe III (> 9,1 m) (BOHNER et al., 2011). Quanto ao DAP foram classificadas em: classe I $(5-15 \mathrm{~cm})$, classe II $(16-25 \mathrm{~cm})$, classe III $(26-35 \mathrm{~cm})$, classe IV $(36-45 \mathrm{~cm})$, classe V (> $46 \mathrm{~cm}$ ) (modificado de UPADHAYA et al., 2004).

Para o estado fitossanitário foi empregada a metodologia descrita por Milano (1988), em que se atribui notas aos indivíduos de 1 a 3 , sendo considerado 1 como árvore boa (vigorosa, que não apresenta sinais de danos mecânicos), 2 como árvore satisfatória (apresenta condição e vigor médios para o local, pode apresentar pequenos problemas de danos físicos) e 3 como ruim (apresenta estado geral de declínio e pode apresentar severos danos físicos).

A frequência de cada espécie (\%) foi calculada pela razão entre o número de indivíduos da espécie e o número total de indivíduos (ROCHA et al., 2004).

O índice de diversidade de espécies seguiu conforme proposto por Margalef (1951):

$$
\text { Alfa }=(S-1) / \log N
$$

Em que: Alfa = Índice de diversidade; $\mathbf{S}=$ número de espécies; $\mathbf{N}=$ número de indivíduos. Os valores inferiores a 2,0 são considerados como denotando áreas de baixa diversidade e valores superiores a 5,0 são considerados como indicador de grande biodiversidade.

As espécies mais comuns e frequentes foram identificadas in loco, e as demais pelo uso de bibliografia adequada. A origem das espécies foi definida segundo distribuição fitogeográfica das mesmas, classificadas em nativas ( $n$ ) e exóticas (e). As espécies foram identificadas de acordo com o sistema de classificação APG III (2009).

Os dados foram anotados em planilhas de campo e depois transferidos para 0 software Microsoft Office Exce ${ }^{\circledR} 2003$, onde foram processados e apresentados em tabelas e gráficos. 


\section{RESULTADOS E DISCUSSÃO}

O levantamento da arborização nas três áreas permitiu conhecer as espécies existentes nestes locais bem como a qualidade e frequência das mesmas (Tabela 1). Inventários de vegetação são meios importantes para verificar os erros e acertos na arborização de uma cidade (MUNEROLI; MASCARÓ, 2010).

Com a avaliação dos dados compilados, pode-se constatar a nítida heterogeneidade da arborização no município de Leme. Foram levantados 333 indivíduos arbóreos, dos quais não foi possível identificar nove indivíduos, correspondente a pouco mais de $2,5 \%$. Os indivíduos identificados estão distribuídos em 62 espécies divididas em 24 famílias botânicas. Conforme reportado por Milano e Dalcin (2000), é indicado que a composição arbórea de uma cidade seja entre 10 e 20 espécies.

A qualidade, a quantidade e a distribuição das espécies arbóreas influenciam a fauna associada, contribuindo assim para a conservação da natureza, pois além de frutos, o néctar e insetos atraídos pelos vegetais servem de alimento para as avifauna (CAVALHEIRO, 1995).

A análise quantitativa demonstrou que as famílias botânicas representadas por maior número de espécies foram: Fabaceae; com 11 espécies, Bignoniaceae; com sete e Arecaceae; com cinco. Essas 23 diferentes espécies representam 37,09\% do total existente (Tabela 1).

Quanto à origem das espécies verificou-se que aproximadamente 64\% dos indivíduos utilizados na arborização das praças são nativos (Tabela 1). De acordo com Faria et al. (2007), a flora nativa tem elevada participação na arborização de cidades brasileiras, além disso, uma diversidade maior de espécies pode atrair uma avifauna mais significativa para as áreas urbanas (MATARAZZO-NEUBERGER, 1995).

Embora alguns estudos apontem a prevalência de espécies exóticas nas vias públicas (ZILLER, 2001; SILVA et al., 2007; BLUM et al., 2008; LINDENMAIER; SANTOS, 2008 REZENDE; SANTOS, 2010), a preferência na arborização urbana deve ser por plantas nativas, pois as espécies exóticas podem causar diversos danos ao ambiente, como a perda da biodiversidade, modificações nos ciclos e características naturais dos ecossistemas atingidos, alteração fisionômica da paisagem natural e, algumas vezes, consequências econômicas vultuosas (ZILLER, 2001; SILVA FILHO; BORTOLETO, 2005).

Na Área 1 e Área 3 predominou a espécie Sibipiruna (Caesalpina peltophoroides Benth) com frequência de $58,82 \%$ e $18,62 \%$, respectivamente. Na Área 2, a maior frequência observada foi de indivíduos arbóreos da família Arecaceae, representada por 29 
indivíduos (15,26\%) de Palmeira Imperial (Roystonea oleracea (Jacq.) O.F.) e 24 indivíduos (12,56\%) de Palmeira Jerivá (Syagrus romanzoffiana (Cham.) Glassman), que juntas correspondem a aproximadamente $27 \%$ da arborização desta área (Tabela 1).

Tabela 1. Relação de espécies encontradas na arborização da cidade de Leme/SP, segundo a família, nome popular, espécie, origem, total de espécimes observados e frequência relativa. $n$ : número de indivíduos. $\mathrm{N}$ : espécie nativa. $\mathrm{E}$ : espécie exótica. Área 1: Praça da Bíblia. Área 2: Praça Igreja Imaculada Conceição. Área 3: Praça Rui Barbosa

Table 1. Relationship of species found in the arborization of the city of Leme / SP, according to family, common name, species, origin, total number of specimens observed and relative frequency. $\mathrm{n}$ : number of individuals. $\mathrm{N}$ : native species. $\mathrm{E}$ : exotic species. Area 1: Bíblia Square. Area 2: Imaculada Conceição Church Square. Area 3: Rui Barbosa Square

\begin{tabular}{|c|c|c|c|c|c|c|c|c|c|c|}
\hline \multirow{2}{*}{ FAMÍLIA / ESPÉCIE } & \multirow{2}{*}{ NOME CINETÍFICO } & \multirow{2}{*}{ Origem } & \multicolumn{2}{|c|}{ Praça 1} & \multicolumn{2}{|c|}{ Praça 2} & \multicolumn{2}{|c|}{ Praça 3} & \multicolumn{2}{|c|}{ TOTAL } \\
\hline & & & $\mathrm{n}$ & FR & $\mathrm{n}$ & FR & $\mathrm{n}$ & FR & $\mathrm{n}$ & FR \\
\hline \multicolumn{11}{|l|}{ Anacardiaceae } \\
\hline Aroeira Salsa & Schinus molle & $\mathrm{N}$ & 1 & $0,30 \%$ & 1 & $0,30 \%$ & 3 & $0,90 \%$ & 5 & $1,50 \%$ \\
\hline Mangueira & Mangifera indica & $E$ & - & - & - & - & 2 & $0,60 \%$ & 2 & $0,60 \%$ \\
\hline Maruleira & Sclerocarrya birrea & $E$ & - & - & - & - & 2 & $0,60 \%$ & 2 & $0,60 \%$ \\
\hline \multicolumn{11}{|l|}{ Apocynaceae } \\
\hline Chapéu-de-napoleão & Thevetia peruviana & $\mathrm{N}$ & 2 & $0,60 \%$ & - & - & 1 & $0,30 \%$ & 3 & $0,90 \%$ \\
\hline Espirradeira & Nerium oleander & $E$ & 1 & $0,30 \%$ & - & - & - & - & 1 & $0,30 \%$ \\
\hline \multicolumn{11}{|l|}{ Arecaceae } \\
\hline Palmeira imperial & Roystonea oleracea & $E$ & - & - & - & - & 29 & $8,70 \%$ & 29 & $8,70 \%$ \\
\hline Palmeira jerivá & Syagrus romanzoffiana & $\mathrm{N}$ & - & - & 2 & $0,60 \%$ & 24 & $7,20 \%$ & 26 & $7,80 \%$ \\
\hline Palmeira seafortia & Seaphortia elegans & $E$ & 4 & $1,20 \%$ & - & - & 4 & $1,20 \%$ & 8 & $2,40 \%$ \\
\hline Palmeira rabo-de-peixe & Caryota mitis & $E$ & - & - & 4 & $1,20 \%$ & 6 & $1,80 \%$ & 10 & $3,00 \%$ \\
\hline Macaúba & Acronomia aculeata & $\mathrm{N}$ & - & - & - & - & 8 & $2,40 \%$ & 8 & $2,40 \%$ \\
\hline \multicolumn{11}{|l|}{ Bignoniaceae } \\
\hline Espatódea & Spathodea campanula & $E$ & 1 & $0,30 \%$ & - & - & - & - & 1 & $0,30 \%$ \\
\hline Ipê amarelo & Tabebuia chrysotricha & $\mathrm{N}$ & - & - & 2 & $0,60 \%$ & 11 & $3,30 \%$ & 13 & $3,90 \%$ \\
\hline Ipê amarelo-do-brejo & & $\mathrm{N}$ & - & - & - & - & 1 & $0,03 \%$ & 1 & $0,03 \%$ \\
\hline Ipê branco & Tabebuia roseo-alba & $\mathrm{N}$ & 2 & $0,60 \%$ & - & - & 2 & $0,60 \%$ & 4 & $1,20 \%$ \\
\hline Ipê roxo & Tabebuia avellanedae & $\mathrm{N}$ & 1 & $0,30 \%$ & - & - & 2 & $0,60 \%$ & 3 & $0,90 \%$ \\
\hline Ipê roxo-de-bola & Tabebuia impetiginosa & $\mathrm{N}$ & - & - & - & - & 1 & $0,30 \%$ & 1 & $0,30 \%$ \\
\hline Jacarandá boca-d-sapo & Jacaranda brasiliana & $\mathrm{N}$ & - & - & - & - & 2 & $0,60 \%$ & 2 & $0,60 \%$ \\
\hline \multicolumn{11}{|l|}{ Caryophyllaceae } \\
\hline Véu-de-noiva & Gypsophila paniculata & $E$ & 2 & $0,60 \%$ & - & - & - & - & 2 & $0,60 \%$ \\
\hline
\end{tabular}




\section{Cicadaceae}

$\begin{array}{lllllllllll}\text { Cica } & \text { Cyca circinalis } & \text { E } & - & - & - & - & 2 & 0,60 \% & 2 & 0,60 \% \\ \text { Cica } & \text { Cyca revoluta } & \text { E } & - & - & - & - & 1 & 0,30 \% & 1 & 0,30 \%\end{array}$

\section{Combretaceae}

Chapéu-de-sol

Terminalia catappa

E $\quad 1 \quad 0,30 \%$

$1 \quad 0,30 \%$

\section{Cupressaceae}

Cipreste-portugues

Cupressus lusitânica

E

$1 \quad 0,30 \% \quad 1 \quad 0,30 \%$

\section{Fabaceae}

Flamboyant

Flamboyant-de-jardim

Guapuruvú

Jatobá

Louveira

Leucena

Pata-de-vaca

Pata-de-vaca

Pau-ferro

Sibipiruna

Tipuana

\section{Lauraceae}

Canelinha

Delonix regia

Caesalpinia pulcherrima

Schizolobium parahyba

Hymenaea courbaril

Cyclolobium Vecchii

Leucaena leucocephala

Bauhinia forficata

Bauhinia variegata

Caesalpinia férrea

Caesalpina peltophoroides

Tipuana tipu

$\begin{array}{lllllllll}\text { E } & - & - & 1 & 0,30 \% & 2 & 0,60 \% & 3 & 0,90 \% \\ \text { E } & 1 & 0,30 \% & - & - & - & - & 1 & 0,30 \% \\ N & 1 & 0,30 \% & - & - & - & - & 1 & 0,30 \% \\ N & - & - & - & - & 2 & 0,60 \% & 2 & 0,60 \% \\ N & - & - & - & - & 1 & 0,30 \% & 1 & 0,30 \% \\ N & - & - & 1 & 0,30 \% & - & - & 1 & 0,30 \% \\ N & 4 & 1,20 \% & - & - & 6 & 1,80 \% & 10 & 3,00 \% \\ N & 10 & 3,00 \% & - & - & - & - & 10 & 3,00 \% \\ N & - & - & - & - & 5 & 1,50 \% & 5 & 1,50 \% \\ N & 19 & 5,70 \% & 20 & 6,00 \% & 22 & 6,60 \% & 61 & 18,30 \% \\ \text { E } & 16 & 4,80 \% & - & - & 3 & 0,90 \% & 19 & 5,70 \%\end{array}$

Nectandra megapotâmica

N $8 \quad 2,40 \% \quad-$

$6 \quad 1,80 \% \quad 14 \quad 4,20 \%$

\section{Lecythidaceae}

Jequitibá branco

Cariniana estrellensis

Jequitibá rosa

Cariniana legal

$\mathrm{N}$

$1 \quad 0,30 \% \quad 1 \quad 0,30 \%$

\section{Lythraceae}

Mirindiba rosa

Lafoensia glyptocarpa

N $1 \quad 0,30 \%$

$3 \quad 0,30 \% \quad 4 \quad 1,20 \%$

\section{Magnoliaceae}

Magnólia

Magnólia grandiflora

E $10,30 \% \quad-$

$1 \quad 0,30 \% \quad 2 \quad 0,60 \%$

\section{Malpighiaceae}

Aceroleira

Malpighia glabra

E $2 \quad 0,60 \%$

$2 \quad 0,60 \%$

Chuva-de-ouro

Lophantera lactescens

$\mathrm{N} \quad-\quad-\quad-\quad-\quad 1 \quad 0,30 \% \quad 2 \quad 0,60 \%$

\section{Malvaceae}

Castanha-do-maranhão

Paineira amarela

Bombacopsis glabra

N $\quad 1 \quad 0,30 \% \quad-\quad-\quad 3 \quad 0,30 \% \quad 4 \quad 1,20 \%$

\section{Melastomataceae}

Quaresmeira

Spirotheca rivieri



\section{Moraceae}

Ficus benjamina

Tibouchina granulosa

N $8 \quad 2,40 \% \quad-$

$5 \quad 1,50 \% \quad 13 \quad 3,90 \%$

Ficus benjamina

E $2 \quad \begin{array}{llllllll}0,60 \% & 4 & 1,20 \% & 1 & 0,30 \% & 7 & 2,10 \%\end{array}$




\begin{tabular}{|c|c|c|c|c|c|c|c|c|c|}
\hline \multicolumn{10}{|l|}{ Myrtaceae } \\
\hline Goiabeira & Psidium guajava & $\mathrm{N}$ & 4 & $1,20 \%$ & - & - & - & 4 & $1,20 \%$ \\
\hline Pitangueira & Eugenia uniflora & $\mathrm{N}$ & - & - & - & 2 & $0,60 \%$ & 2 & $0,60 \%$ \\
\hline \multicolumn{10}{|l|}{ Nyctaginaceae } \\
\hline Maria-mole & Guapira opposita & $\mathrm{N}$ & - & - & - & 1 & $0,30 \%$ & 1 & $0,30 \%$ \\
\hline \multicolumn{10}{|l|}{ Oleaceae } \\
\hline Alfeneiro & Ligustrum lucidum & $E$ & 1 & $0,30 \%$ & - & 2 & $0,60 \%$ & 3 & $0,90 \%$ \\
\hline \multicolumn{10}{|l|}{ Rhamnaceae } \\
\hline Sobrasil & Colubrina glandulosa & $\mathrm{N}$ & - & - & - & 1 & $0,30 \%$ & 1 & $0,30 \%$ \\
\hline \multicolumn{10}{|l|}{ Rutaceae } \\
\hline Cajueiro & Anacardium occidentale & $\mathrm{N}$ & 1 & $0,30 \%$ & - & - & - & 1 & $0,30 \%$ \\
\hline Limoeiro & Citrus limon & $E$ & 2 & $0,60 \%$ & - & - & - & 2 & $0,60 \%$ \\
\hline Pau-marfim & Balfourodendron riedelianum & $\mathrm{N}$ & - & - & - & 2 & $0,60 \%$ & 2 & $0,60 \%$ \\
\hline \multicolumn{10}{|l|}{ Verbenaceae } \\
\hline Pingo-de-ouro & Duranta repens aurea & $E$ & 7 & $2,10 \%$ & - & - & - & 7 & $2,10 \%$ \\
\hline
\end{tabular}

Segundo critérios adotados por Margalef (1988), os valores obtidos na Tabela 1 evidenciam a grande diversidade na arborização do município (Tabela 2).

Tabela 2. Índice de Diversidade de Margalef nas três áreas amostrais

Table 2. Margalef Diversity Index in the three studied areas

\begin{tabular}{cc}
\hline Área Amostral & IDM $^{*}$ \\
\hline Área 1 & 12,86 \\
Área 2 & 17,08 \\
Área 3 & 4,49 \\
Total (Área 1 + Área 2 + Área 3) & 24,18
\end{tabular}

* Índice de Diversidade de Margalef. Valores inferiores a 2,0 são considerados como áreas de baixa diversidade e superiores a 5,0 são considerados como indicador de grande biodiversidade.

A frequência de uma única espécie não deve ultrapassar a 15\%. Por razões estéticas e fitossanitárias, deve-se estabelecer o número e a proporção para cada espécie em relação ao total de árvores plantadas (MILANO; DALCIN, 2000; REDING et al., 2010). Desta maneira, observa-se que na Área 1 e Área 3 a espécie C. peltophoroides ultrapassou o número adequado de indivíduos, inferindo grandes riscos relacionados à longevidade por meio de declínio e ataque de pragas ou doenças.

Alguns estudos sobre a arborização urbana no interior do Estado de São Paulo revelam padrões similares. Em Penápolis foram encontradas 34 espécies arbóreas (PAIVA; 
DRAGONI, 1997). Avaliando dois bairros da cidade de Americana, Silva (2005) observou 32 espécies. Já em levantamento na cidade de Campos do Jordão, foram levantadas 32 espécies nas vias públicas (ANDRADE, 2002). Em todos os casos foram observadas frequências elevadas de indivíduos em poucas espécies.

Foram identificados apenas sete exemplares de frutíferas, que correspondem a aproximadamente $2 \%$ do total de indivíduos (Tabela 1). As condições viárias urbanas não constituem meio adequado ao processo produtivo de frutíferas, pois os frutos maduros que caem e permanecerem no local, além da sujeira, servem de alimento para vetores de doenças como moscas, baratas e ratos, facilitando o aumento dessas populações (MILANO; DALCIN, 2000).

A distribuição da altura das árvores em Leme é considerada adequada, pois ocorreu a presença de indivíduos em todas as classes de altura. É possível inferir ainda que o porte das árvores observadas está adequado aos modelos de uma correta arborização urbana. Resultados similares também foram descritos na avaliação da arborização urbana em cinco praças do município de Cachoeira do Sul, RS (REDING et al., 2010).

A classe de altura III (>9m) teve destaque quanto ao número de indivíduos amostrados nas três áreas. Do ponto de vista ambiental, é recomendado a utilização de espécies de médio e grande porte, pois espécies de pequeno porte e arbustos, por suas características, contribuem pouco para melhoria climática e ambiental das cidades (MILANO; DALCIN, 2000).

Avaliando a arborização da cidade de Cosmópolis, SP, concluiu-se que a maioria dos indivíduos amostrados (52\%) estão concentrados no grupo de espécies de grande porte (PAIVA, 2009).

Os resultados sugerem ainda que a arborização das vias públicas é composta por árvores onde a grande maioria denota idade já avançada, principalmente na Área 2.

Diferentemente das árvores encontradas no meio natural, os exemplares arbóreos nas calçadas públicas estão mais propensos a injúrias físicas devido à ação antrópica. Todavia, com base nos resultados obtidos, $56 \%$ das árvores nas três praças apresentam bom estado fitossanitário, ou seja, estão vigorosas e não apresentam sinais de danos mecânicos demonstrando boas condições de raízes e parte aérea, não requerendo emergencialmente interferências visando melhorias. Cerca de 30\% dos indivíduos apresentam estado fitossanitário satisfatório; com condições e vigor médio e com pequenos danos físicos, e apenas 14\% foram classificadas como ruins, apresentando estado geral de declínio, com sintomas comuns ao ataque de pragas e organismos patogênicos, perfurações 
no tronco e raízes, queda prematura das folhas e condições visivelmente danificadas da parte aérea.

Parasitas como a erva-de-passarinho (Phoradendron sp.) foram encontradas, sobretudo, em indivíduos mais velhos, além de ataque de formigas, cupins e fungos, e ataque de lagartas em algumas palmeiras.

Comparativamente, o município de Leme encontra-se em situação favorável. Em um estudo realizado por Faria et al. (2007) nas vias públicas de Jacareí, SP, foram constatados que aproximadamente $60 \%$ dos indivíduos apresentavam ataque de insetos, doenças ou problemas fisiológicos leves ou graves, enquanto que apenas $40 \%$ desses indivíduos estavam saudáveis.

Árvores com DAP entre 5 e $15 \mathrm{~cm}$ (classe I) corresponderam a 18,3\%, com DAP entre 16 e $25 \mathrm{~cm}$ (classe II), a 21,62\%, com DAP variando entre 26 e $35 \mathrm{~cm}$ (classe III) e 36 e $45 \mathrm{~cm}$ (classe IV), correspondem aproximadamente a 15\% e 14,4\%, respectivamente.

Cerca de $30 \%$ das árvores (100 indivíduos) apresentaram DAP superior a $46 \mathrm{~cm}$ (classe V), valores que associados à altura das árvores, confirmam que esta grande parcela é resultado de um trabalho não muito recente de arborização urbana, ou seja, indicam que se trata de uma população arbórea já estabelecida, com maior participação de indivíduos adultos. A mesma situação foi detectada em Americana/SP, onde $55 \%$ dos indivíduos apresentaram DAP superior a 0,25 m (SILVA, 2005).

Ressalta-se que predomínios de indivíduos na classe diamétrica I é atribuído à jovialidade da arborização e que a necessidade de alto percentual de indivíduos jovens em programas de arborização é devida à alta mortalidade nesse período (ALMEIDA; RONDON NETO, 2010). Tais constatações estão de acordo com o fato de que um número razoável de indivíduos adultos, formando uma população estável, advém da sobrevivência dos indivíduos jovens que foram capazes de se adaptar às condições urbanas (FORMAN; GODRAN, 1986).

A SBAU - Sociedade Brasileira de Arborização Urbana recomenda que o número ideal de árvores por km de calçada seja de pelo menos 100 indivíduos. Fica visível que a cidade de Leme é carente de cobertura vegetal, ao se tomar como referência a informação da United Nations Educational, Scientific and Cultural Organization (UNESCO), que recomenda a existência de pelo menos duas árvores ou cobertura de $12 \mathrm{~m}^{2}$ por habitante, para uma melhor qualidade de vida. 


\section{CONCLUSÕES}

A arborização urbana nas praças centrais do município de Leme/SP é composta por uma grande diversidade de espécies nativas que se encontram em idade avançada, devendo ser substituídos por novas árvores. Embora os indivíduos tenham grande porte e, de um modo geral, bom estado fitossanitário, o município ainda não conta com a cobertura vegetal adequada por habitante.

Como estratégia para melhorar a arborização das praças centrais de Leme, sugerese implementação de um plano diretor municipal para a arborização urbana, associado a programas de educação ambiental junto à comunidade, estabelecendo regras, realizando acompanhamento, manejo e controle de maneira efetiva.

\section{REFERÊNCIAS}

ALMEIDA, L. F. R.; BICUDO, L. R. H.; BORGES, G. L. A. Educação ambiental em praças públicas: professores e alunos descobrindo o ambiente urbano. Revista Ciência em extensão, Assis, SP, v.1, n.1, p.91-100, 2004.

ALMEIDA, D. N.; RONDON NETO, R. M. Análise da arborização urbana de duas cidades da região norte do estado de Mato Grosso. Revista Árvore, Viçosa, MG, v. 34, n. 5, p. 899906, 2010.

ANDRADE, T. O. Inventário e análise da arborização viária da estância turística de Campos do Jordão, SP. 2002. 129 p.Dissertação (Mestrado em Agronomia - Fitotecnica) Escola Superior de Agricultura Luiz de Queiroz - ESALQ USP, Piracicaba, SP, 2002.

ANGIOSPERM PHYLOGENY GROUP (APG) III. An update of the Angiosperm Phylogeny Group classification for the orders and families of flowering plants: APG III Botanical. Journal of the Linnean Society, (s.n.), não paginado, 2009.

BIONDI. D; ALTHAUS, M. Árvores Urbanas de Curitiba - Cultivo e manejo. 1. ed. Curitiba: FUPEF, 2005. 117p.

BOHNER, T., GRACIOLI, C.R.; REDIN, C.G.; SILVA, D.T.; LONGHI, S.J.; ROSA, M.B. Analise quali-quantitativa da arborização do município de Guatambu, SC. Monografias Ambientais, v. 3, n.3, p.532-546, 2011.

BLUM, C.T.; BORGO, M.; SAMPAIO, A.C.F. Espécies exóticas invasoras na arborização de vias públicas de Maringá-PR. Revista Brasileira de Arborização Urbana, Piracicaba, SP, v.3, n.2, p.78-97, 2008. 
CAVALHEIRO, F. Urbanização e alterações ambientais. In: TAUK, S. M. Análise Amt794ybiental: uma visão multidisciplinar. 2. ed. São Paulo: Editora da Universidade Estadual Paulista, 1995. p.114-124.

COSTA, E.C; LINK, D; MEDINA, L.D. de. Índice de Diversidade para entomofauna da Bragatinga (Mimosa scabrella Benth.). Ciência Florestal, Santa Maria, RS, v.3, n.1, p. 6575, 1993.

DANTAS, I.C.; SOUZA, C.M.C. Arborização urbana na cidade de Campina Grande - PB: Inventário e suas espécies. Revista de Biologia e Ciências da Terra, Campina Grande, PB, v.4, p. 76-89, 2004, n/p.

FARIA, J.L.G.; MONTEIRO, E.A.; FISCH, S.T.V. Arborização de vias públicas do município de Jacareí-SP. Revista Brasileira de Arborização Urbana, Piracicaba, SP, v.2, n.4, p. 2033, 2007.

FORMAN, R. T. T.; GODRAN, M. Landscape ecology. New York: John Wiley, 1986. 620p.

GONÇALVES, E. O.; PAIVA, H. N.; GONÇALVES, W.; JACOVINE, L. A. G. Avaliação de mudas destinadas à arborização urbana no Estado de Minas Gerais. Revista Árvore, Viçosa, MG, v.28, n.4, p. 479-486, 2004.

IBGE - Instituto Brasileiro de Geografia Estatística. Disponível em: <http://www.ibge. gov.br/cidadesat/painel/painel.php?codmun=352670 > . Acesso em: 11 mar 2013.

LINDENMAIER, D.S.; SANTOS, N.O. Arborização urbana das praças de Cachoeira do Sul RS - Brasil: fitogeografia, diversidade e índices de áreas verdes. Pesquisas, Botânica, São Leopoldo, v.1, n. 59. p. 307-320, 2008.

MARGALEF, R. Diversidad de especies en las comunidades naturales. Publicaciones del Instituto de Biologia Aplicada e Barcelona, Barcelona, v.6, p.59-72.1951.

MATARAZZO-NEUBERGER, W. M. Comunidades de aves de cinco parques e praças da Grande São Paulo, Estado de São Paulo. Ararajuba, v.3, n.1, p.13- 19, 1995.

MALAVESI, U. C.; MALAVESI, M. M. Avaliação da Arborização urbana pelos residentes estudo de caso. Revista Ciência Florestal, Santa Maria, RS, v.11, n.1, p.189-193, 1994.

MESQUITA, L. B. Memórias do verde urbano do Recife. In: CONGRESSO BRASILEIRO SOBRE ARBORIZAÇÃO URBANA, 3., Salvador, 1996. Anais. Salvador, 1996. p. 60-70. MILANO, S. M.; DALCIN, E. Arborização de via públicas. Rio de Janeiro, RJ. Light. 2000. 226p. 
MONTOYA VILCAHUAMAN, L.J.; BAGGIO, A.J.; SOARES, A.. Guia prático sobre arborização de pastagens. Colombo: Embrapa Florestas, 2000. 15p. (Embrapa Florestas. Documentos, 49).

MOREIRA, A.C.M.L. Mega-projetos \& Ambiente Urbano: uma metodologia para elaboração de relatório de impacto de vizinhança. 1997. 66p. Tese - (Doutorado em Arquitetura e Urbanismo) - Faculdade de Arquitetura e Urbanismo, Universidade de São Paulo, São Paulo, 1997.

MUNEROLI, C. C.; MASCARÓ, J. J. Arborização urbana: uso de espécies arbóreas nativas na captura do carbono atmosférico. Revista Brasileira de Arborização Urbana, Piracicaba, SP, v.5, n.1, p.160-182, 2010.

PAIVA, A. V. Aspectos da arborização urbana do centro de Cosmópolis -SP. Revista Brasileira de Arborização Urbana, Piracicaba, SP, v.4, n.4, p.17-31, 2009.

PAIVA, H. N. Seleção de espécies para arborização urbana. Revista Ação Ambiental, UFV, Viçosa, MG, v.2, n.9, 2000. n/p.

PAIVA, A. V.; DRAGONI, V. F. Projeto de inventário, diagnóstico e rearborização urbana da região central do município de Penápolis, SP. In: ENCONTRO NACIONAL SOBRE ARBORIZAÇÃO URBANA, 7., 1997, Belo Horizonte. Anais... Belo Horizonte: Sociedade Brasileira de Arborização Urbana, 1997. p.80.

PREFEITURA DO MUNICÍPIO DE LEME. LEME: mais de um século de pleno desenvolvimento. Disponível em: < http://www.leme.sp.gov.br/conhecaleme/index.php> Acesso em: 13 mar 2013.

PREFEITURA MUNICIPAL DE MANAUS. Arborização Urbana. Disponível em: <http://www.manaus.am.gov.br/noticias/arborizacao-urbana-6>. Acesso em: 12 jan 2013.

REDING, C. G.; VOGEL, C.; TROJAHN, C. D. P.; GRACIOLI, S. J. L. Análise da arborização urbana em cinco praças do município de Cachoeira do Sul, RS. Revista Brasileira de Arborização Urbana, v.5, n.3, p.149-164, 2010.

REZENDE, T. M.; SANTOS, D.G. Avaliação quali-quantitativa da arborização das praças do bairro Jaraguá, Uberlândia - MG. Revista Brasileira de Arborização Urbana, Piracicaba, SP, v.5, n.2, p.139-157, 2010.

ROCHA, R. T.; LELES, P. S. S.; OLIVEIRA NETO, S. N. Arborização de vias públicas em Nova Iguaçu: o caso dos bairros Rancho Novo e Centro. Revista Árvore, Viçosa, MG, v.28, n.4, p. 599-607, 2004. 
SANTOS, N.R.Z.; TEIXEIRA, I.F. Arborização de Vias Públicas: Ambiente x Vegetação. RS: Clube da árvore, 2001. 135p.

SCHALLENBERGER, L. S.; ARAÚJO, A. J. de; ARAÚJO, M. N. de; DEINER, L. J.; MACHADO, G. de O. Avaliação da condição de árvores urbanas nos principais parques e praças do município de Irati-PR. Revista da Sociedade Brasileira de Arborização Urbana, Piracicaba, SP, v. 5, n. 2, p. 105-123, 2010.

SILVA, E. M. Estudo da arborização urbana do bairro Mansour na cidade de UberlândiaMG. Caminhos de Geografia, Uberlândia, MG, v.3, n.5, p.73-83, 2002.

SILVA, L. F. Situação da arborização viária e proposta de espécies para os bairros Antônio Zanaga I e II, da cidade de Americana/SP. 2005. 80f. Dissertação (Mestrado em Agronomia) - Escola Superior de Agricultura Luiz de Queiroz, ESALQ/USP, Piracicaba, 2005.

SILVA, V. A. Geografia do Brasil e Geral: povos e territórios. São Paulo: Escala Educacional, 2005. 400p.

SILVA, N. C. Diagnóstico da arborização de praças do município de Anápolis, Goiás. Anais I Simpósio Nacional de Ciência e Meio Ambiente: Progresso, Consumo e Natureza Desafios ao Homem. 2010.

SILVA FILHO, D. F.; BORTOLETO, S. Uso de indicadores de diversidade na definição de plano de manejo de arborização viária de águas de São Pedro-SP. Revista Árvore, Viçosa, MG, v.29, n.6, p. 873-982, 2005.

SILVA, L. M.; HASSE, I.; MOCCELIN, R.; ZBORALSKI, A. R. Arborização de vias públicas e a utilização de espécies exóticas: o caso do bairro centro de Pato Branco/PR. Scientia Agraria, Curitiba, PR, v.8, n.1, p.47-53, 2007.

SOARES, C. P. B.; NETO, F. P.; SOUZA, A. L. Dendrometria e Inventário Florestal. Viçosa, MG. Ed. UFV, 276p. 2007.

SOUZA, A. A.; POLETTO, R.S. Levantamento de espécies invasoras nas praças de Garça SP - Magnoliopsida e Liliopsida. Revista Científica Eletrônica de Engenharia Florestal, v.5, n.9, 2007.n/p.

UPADHAYA, K., PANDEY, H.N.; LAW, P.S.; TRIPATHI, R.S. Diversity and population characteristics of woody species in subtropical humid forests exposed to cultural disturbances in Meghalaya, Northeast, India. Tropical Ecology, v.45, n.2, p.303-314, 2004.

ZILLER, S. R. Os processos de degradação ambiental originados por plantas invasoras. Revista Ciência Hoje, Rio de Janeiro, RJ, v.30, n.178, p. 77-79, 2001. 